\title{
The importance of students' motivational dispositions for designing learning analytics
}

\section{Clara Schumacher ${ }^{1}$ (D) Dirk Ifenthaler ${ }^{1,2}$}

Published online: 10 September 2018

(C) The Author(s) 2018

\begin{abstract}
Depending on their motivational dispositions, students choose different learning strategies and vary in their persistence in reaching learning outcomes. As learning is more and more facilitated through technology, analytics approaches allow learning processes and environments to be analyzed and optimized. However, research on motivation and learning analytics is at an early stage. Thus, the purpose of this quantitative survey study is to investigate the relation between students' motivational dispositions and the support they perceive through learning analytics. Findings indicate that facets of students' goal orientations and academic self-concept impact students' expectations of the support from learning analytics. The findings emphasize the need to design highly personalized and adaptable learning analytics systems that consider students' dispositions and needs. The present study is a first attempt at linking empirical evidence, motivational theory, and learning analytics.
\end{abstract}

Keywords Learning analytics · Learning motivation · Achievement motivation - Self-concept

\section{Introduction}

Learning theories such as self-regulated learning highlight the importance of motivation for learning (Boekaerts 1999; Pintrich 2000c; Schunk et al. 2008; Zimmerman 2002). Motivation is a multifaceted concept several disciplines pay attention to as it is considered to be the driver for a person's actions and not obvious

Clara Schumacher

clara.schumacher@bwl.uni-mannheim.de

Dirk Ifenthaler

dirk@ifenthaler.info

1 Economic and Business Education - Learning, Design and Technology, University of Mannheim, L4, 1, 68161 Mannheim, Germany

2 UNESCO, Deputy Chair of Data Science in Higher Education Learning and Teaching, Curtin University, Bentley, Perth, Australia 
from external. Focusing on a cognitive approach, motivation can be defined as "the process whereby goal-directed activity is instigated and sustained" (Schunk et al. 2008 , p. 4). This definition implies that motivation is a process as well as goaloriented and that both initiating activities and persisting in activities are crucial to achieving the designated goals.

Motivational factors, such as interest, autonomy, competence, relatedness, and self-efficacy, determine students' regulation effort towards a learning goal (Eseryel et al. 2014; Vansteenkiste et al. 2004; Zimmerman and Schunk 2008). Hence, differences in learning outcomes are related to students' capability to self-regulate their learning, individual characteristics, and motivational dispositions (Schunk and Zimmerman 2008; Zimmerman 2002). Especially in highly self-regulated learning environments, such as higher education or online learning, motivation is crucial for successful learning (Chen and Jang 2010; Joo et al. 2015; Keller 2008a; Keller and Suzuki 2004; Moos and Bonde 2016). Self-regulated learning processes are considered to be interdependently connected to motivational processes, as motivation affects learning strategy selection, learning processes, and outcomes. Likewise, self-regulation can influence learners' motivation (Lehmann et al. 2014; Zimmerman 1990, 2011; Zimmerman and Schunk 2008).

In the past few years, higher education has seen various changes, due to larger study cohorts but also higher withdrawals (Mah 2016), as well as the advancement of applying technologies for learning. One important driver for changing learning and learning environments is the availability of vast amounts of educational data and unforeseen possibilities to make use of them (Long and Siemens 2011). Learning analytics are a key concept related to this increase in educational data. They use static and dynamic information about learners and learning environments, assessing, eliciting, and analyzing it, for real-time modeling prediction, and optimization of learning processes, learning environments, and educational decision-making (Ifenthaler 2015). Current research on learning analytics focusses on technical issues and data processing (Berland et al. 2014; Costa et al. 2017), on data privacy (Drachsler and Greller 2016; Ifenthaler and Schumacher 2016; Rubel and Jones 2016; West et al. 2016), on developing user systems (d'Aquin et al. 2014), on relationships between learner characteristics and learning outcome (Ellis et al. 2017; Gašević et al. 2017; Liu et al. 2017), or on specific applications for dashboards (Park and Jo 2015; Schumacher and Ifenthaler 2018; Verbert et al. 2013). However, linking learning analytics with learning theories is still at an early stage (Marzouk et al. 2016). Additionally, student motivation is not yet sufficiently considered for analyses of learning analytics (Lonn et al. 2015). In a qualitative study, Corrin and da Barba (2014) investigated how feedback through learning analytics dashboards impacts students' motivation. Their findings indicate that students mostly perceived a positive effect on their motivation in terms of effort regulation or awareness of their progress. However, some participants also indicated that it did not influence their motivation at all. Accordingly, further empirical studies are required to identify the capabilities of learning analytics for facilitating learning processes and especially for supporting and not impairing learning motivation. 
To add evidence to this gap in research, the focus of this study was to investigate students' motivational dispositions and its relationship to perceived support from learning analytics systems.

\section{Theoretical framework}

\section{Motivation in (self-regulated) learning processes}

Motivation is considered to be a result of an interaction between environmental and individual factors (Cook and Artino Jr 2016; Hartnett et al. 2011; Keller 2008b; Svinicki and Vogler 2012). Thus, internal as well as external factors can influence a person's motivation, such as self-efficacy beliefs (Bandura 1977; Zimmerman et al. 2017), perceived autonomy (Deci and Ryan 2008; Deci et al. 1996), attributions (Schunk 2008; Weiner 1985), value of the task, and expected difficulty in reaching the goal (Eccles and Wigfield 2002; Engelschalk et al. 2016; Wigfield et al. 2009), goal orientations (Elliot 2005; Elliot and Hulleman 2017), academic self-concept, or the design of the learning environment (Keller and Suzuki 2004).

Self-regulating their learning demands a great effort of students; thus, they need to be motivated to initiate and sustain within these processes (Pintrich 1999). Selfregulation requires metacognitive monitoring, control of learning activities, and motivational states to reach the designated learning outcomes. Learners need to adjust their behavior, cognition, or motivation accordingly (Lehmann et al. 2014; Winne and Hadwin 2008). Learning motivation and goal setting in self-regulated learning are influenced by task conditions and requirements, students' beliefs about self-efficacy, outcome expectancies, and individual characteristics (e.g., dispositions, prior experiences, and knowledge) (Winne and Hadwin 2008; Zimmerman et al. 2017). While engaging in the performance phase, motivation is crucial to maintaining learning activities. Additionally, self-regulated learners use several strategies to control and regulate their motivation, such as (a) extrinsic regulation (self-rewarding, reminding of performance goals), (b) intrinsic regulation (increase task value, interest, or self-efficacy beliefs), (c) volition (change the environment, attention), and (d) information processing (help-seeking, cognitive strategies) (Corno 1993; Winne and Hadwin 2008; Wolters 1998). Thus, motivational constructs are considered to have an impact on self-regulated learning processes (Duffy and Azevedo 2015; Zimmerman 2011; Zimmerman and Schunk 2008).

This study focusses on students' goal orientations and their academic selfconcept as crucial motivational components of self-regulated learning (Eccles and Wigfield 2002; Pintrich 1999, 2000c). Key aspects of motivational components are described below and will be linked to learning analytics.

\section{Goal orientation}

Achievement goals aim to explain "the purpose or reason students are pursuing an achievement task as well as the standards or criteria they construct to evaluate their competence or success on the task" (Pintrich 2000a, p. 94). They are described as 
patterns of beliefs and feelings about success, effort, ability, errors, feedback, and standards of evaluation (Elliot 2005). Thus, achievement goal theories assume that students have different learning behaviors because they have different goal orientations when engaging in learning processes (Cook and Artino Jr 2016; Dweck and Leggett 1988; Elliot 2005; Elliot and Hulleman 2017; Schunk et al. 2008).

The assumption is that there are two different types of achievement goal orientations (see Table 1). (1) Learning goal orientation (also labeled as mastery goal orientation): these learners focus on the intrinsic value of learning, such as gaining new knowledge and skills. Learners who have a learning goal orientation assume that intelligence and skills are controllable via learning activities as success is related to effort whereas failure is considered to be an opportunity to learn (Dweck and Leggett 1988). These learning goals are divided into (1a) learningapproach goals, where learners focus on gaining competence by seeking challenging tasks and persisting in goal-achievement behavior even when facing obstacles and (1b) learning-avoidance goals when learners try to avoid losing skills or abilities and being wrong, not relative to others but only in reference to themselves or the task (Elliot 2005; Pintrich 2000a; Senko et al. 2011).

(2) Performance goal orientation: these learners focus on achieving better learning outcomes than others and avoid appearing as unintelligent. This goal orientation is associated with perceiving intelligence as being static, avoiding challenges and giving up quickly, as failure is seen as a lack of ability; only if learners are self-confident in their intelligence or competence they seek challenges (Dweck and Leggett 1988; Elliot 2005). Performance goals are further divided into (2a) performance-approach goals, as those of students who are willing to show their competences to others or to outperform their peers; and (2b) performance-avoidance goals, related to students who try to hide their incompetency by avoiding challenges or uncertainty. Additionally, work-avoidance goals refer to students' tendency to reach goals by avoiding work or effort at all (Harackiewicz et al. 1997; Spinath et al.

Table 1 Exemplary overview about the characteristics of achievement goals

\begin{tabular}{|c|c|c|}
\hline & Approach & Avoidance \\
\hline $\begin{array}{l}\text { Learning goal } \\
\text { orientation }\end{array}$ & $\begin{array}{l}\text { Learning-approach goals: } \\
\text { Develop skills and abilities } \\
\text { Understand a task } \\
\text { Seek for challenging tasks } \\
\text { Develop competence }\end{array}$ & $\begin{array}{l}\text { Learning-avoidance goals: } \\
\text { Avoid losing skills and } \\
\text { abilities } \\
\text { Avoid being wrong } \\
\text { Avoid not understanding a } \\
\text { task or material } \\
\text { Avoid intrapersonal } \\
\text { incompetence }\end{array}$ \\
\hline $\begin{array}{l}\text { Performance goal } \\
\text { orientation }\end{array}$ & $\begin{array}{l}\text { Performance-approach goals: } \\
\text { Show competence to others by seeking appropriate } \\
\text { tasks to appear talented } \\
\text { Outperforming peers }\end{array}$ & $\begin{array}{l}\text { Performance-avoidance } \\
\text { goals: } \\
\text { Avoid showing } \\
\text { incompetence to others } \\
\text { Avoid challenges }\end{array}$ \\
\hline
\end{tabular}


2012). This goal orientation is assumed to be distinct from the above achievement goals as it is specifically characterized by the absence of achievement goal adoption (Elliot 1999).

In general, approach goals (learning and performance goal orientation) are positively related to performance or achievement while avoidance goals (learning and performance goal orientation) are negatively related (Van Yperen et al. 2014). Linnenbrink-Garcia et al. (2008) reported in a meta-analysis that more studies found significant relations of learning-approach goals with achievement than with performance-approach goals, in addition some found negative relations of performance-approach goals with achievement. Further, performance goal orientation is associated with higher academic outcomes in competitive educational contexts whereas learning goal orientation is related to interest and deeper learning strategies (Harackiewicz et al. 1998). Performance-avoidance goals are associated to a negative learning outcome (Elliot and Hulleman 2017). Learners with performance orientation are likely to attribute failure and effort to personal incompetence or low ability and thus as non-controllable (Dweck and Leggett 1988). Help seeking, which is considered to be a self-regulatory strategy (Zimmerman and Schunk 2008), is related to the goal orientations of learners, as learning-approach goal oriented learners think of this as a possibility to enhance their competence whereas avoidance-oriented learners might fear showing low ability (Zimmerman and Schunk 2008). Depending on the context and situation, one goal orientation might be predominant. However, some learners might generally tend to adopt a learning oriented goal approach whereas others are more likely to behave more performance goal oriented (Pintrich 2000a).

Goal orientations are related to perceived competence as learners who feel highly competent are more likely to adopt approach goals (e.g., 1a or 2a) whereas low perceived competence leads to higher expectancies of failure and adoption of avoidance goals (e.g., 1b or 2b) (Elliot 2005). A person's competence can be evaluated against (a) an absolute standard, based on the requirements of a task, (b) an intrapersonal standard with reference to past performance or maximum potential performance of the self, and (c) a normative standard which is related to the performance of others (Elliot 2005; Elliot et al. 2011).

\section{Academic self-concept}

The perceived abilities of learners influence their interest, persistence, motivation to learn, and choice of learning strategies (Cook and Artino Jr 2016; Schunk et al. 2008). The academic self-concept describes a cognitive representation of a person's perceived abilities in an academic achievement situation (Bandura 1994; Skaalvik and Skaalvik 2005). Relevant for learning outcomes is that intrinsic motivation is associated with perceived competence of learners and can be supported by skillmatching but also by challenging tasks and feedback (Hau and Marsh 2015). Deci et al. (1996) postulate a causal effect of the academic self-concept on intrinsic motivation.

When estimating the academic self-concept, a person refers to three reference norms: (a) social reference, comparing own performance with that of relevant 
others; this reference is crucial for building the academic self-concept since learners rely on external feedback about their performance, such as test results, attributions and, feedback from relevant persons (e.g., teachers, peers, parents) (Dickhäuser et al. 2002); (b) individual reference, comparing own performance over domains and time; and (c) criterion-based reference, comparing own performance to objective criteria such as learning objectives. Furthermore, the academic selfconcept includes (d) performance perceptions of the learner without a reference category (Dickhäuser et al. 2002; Eccles and Wigfield 2002; Weidinger et al. 2016).

The academic self-concept seems to have conceptual analogies with academic self-efficacy beliefs of learners, postulated as vital for motivation in Bandura's (1993) social-cognitive view on learning and motivation (Weidinger et al. 2016). There are, however, differences. While the academic self-concept represents a person's perceived competence within an academic domain, characterized as more past-oriented and relatively stable, academic self-efficacy is a learner's perceived confidence to successfully perform a certain academic task, considered to be more context-specific, future-oriented, and malleable (Bandura 1977, 1994). Bong and Skaalvik (2003) state that the academic self-concept influences self-efficacy beliefs but not vice versa. Self-efficacy beliefs are built upon prior experiences and outcomes (Zimmerman and Schunk 2008). However, both concepts are considered to have impacts on intrinsic motivation, strategy use, engagement, persistence, task choice, goal-setting, performance, and achievement (Ferla and Valcke 2009).

Constructs of personal expectancy comparable to the academic self-concept are included in motivational theories. Such constructs include the expectancy of success in the expectancy value theory of motivation (Bong and Skaalvik 2003), and also goal orientations, especially the performance-oriented goals are influenced by a person's belief in being able to reach a certain goal. Hence, self-efficacy beliefs or more generally academic self-concept might influence all phases of self-regulated learning as students select tasks or set goals depending on their perceived abilities and differ in persistence as well as in dealing with challenges (Zimmerman and Schunk 2008). Outcome expectancies are related to self-efficacy beliefs and are a source of motivation as learners will not pursue goals they do not feel capable of reaching (Bandura 1993; Schunk 1991).

\section{Motivational design of (online) learning environments}

The ARCS (attention, relevance, confidence, satisfaction) model aims to integrate and thus illustrate the relations between the theoretical concepts of volition, motivation, learning, and performance in order to facilitate research and instructional design to generate motivating (online) learning environments (Keller 2008b). The original model consists of four components (Keller 2008b; Keller and Suzuki 2004; Li and Keller 2018): (1) attention, referring to the level of curiosity aroused; (2) relevance of a given learning objective to a learner, including its perceived value; (3) confidence in the individual belief of being successful in the learning activity, including the attributions assigned to the learning outcome, and (4) satisfaction about the evaluated overall quality of the learning outcome and process. 
These four components are complemented by volition: self-regulatory strategies to persist in goal-oriented behavior (Keller and Suzuki 2004).

Thus, the expanded theory of motivation, volition, and performance provides a supplement because it explains how external and internal self-regulatory processes can support learners not only in selecting goals but in acting and persisting to reach their goals (Keller 2008a). Its motivational foundation is based on the expectancy value theory, self-efficacy beliefs, goal orientation, attribution theory, and assumptions of self-determination theory. In going beyond goal setting and towards action, the model refers to action control theory and volitional strategies. Furthermore, it is assumed that external learning stimuli are processed with reference to cognitive load and information processing theory but are influenced by motivational components. Finally, this process should lead to learners who initiate and sustain learning processes and perform successfully, thus achieving satisfying learning outcomes.

The motivational design process originally consisted of ten steps, including analysis of learners and learning environment, defining motivational goals, design steps in identifying and selecting motivational tactics to reach these goals, implementation, and post-instructional steps to evaluate the design (Keller 1987, 2008a). Whereas other models [e.g., FEASP-approach (fear, envy, anger, sympathy, and pleasure) (Astleitner 2000)] more broadly consider emotions in learning in general, this theory aims to support research, diagnosing motivational issues, and designing motivational learning environments.

\section{Motivation in learning analytics}

As demonstrated, motivation is a crucial factor in engaging in learning activities and pursuing learning goals. However, combining motivational theory, learning theory, and learning analytics is still at an early stage (Marzouk et al. 2016). Learning analytics provide several benefits to all stakeholders including three perspectives: summative, real-time, and predictive (Ifenthaler and Widanapathirana 2014). In relation to learners' benefits and motivational dispositions, learning analytics may support for example: (a) evaluating learning outcomes against efforts, (b) monitoring the current progress towards goals, (c) integrating just-in-time feedback from assessments into learning processes, (d) adapting learning activities according to learning recommendations and thus increasing learning success.

To react accordingly and provide motivational interventions, learning analytics require information about the learners, their characteristics, and especially about their current motivational state, as well as the perceived relevance of the learning tasks (Keller 2008b; Liu et al. 2017). Learning analytics may provide motivational interventions using data about learners, their behavior in the learning environment, and their interaction with the learning material. Because of the high adaptability of a learning analytics system (Ifenthaler and Widanapathirana 2014), it can react to motivational changes during the learning process.

Learning analytics systems should offer guidance by giving appropriate and personalized feedback on successful and amendable results as learners' self-efficacy beliefs are based on prior success as well as on feedback on their previous 
performance (Bandura 1993, 1994; Schunk 1991; Zimmerman et al. 2017). However, the feedback provided through learning analytics should not be perceived as too intrusive or controlling (Roberts et al. 2017) as the perceived autonomy of learners is central for learning motivation (Deci et al. 1996). To take into account students' motivation and the need for autonomy, learning analytics should allow the beneficiaries to set their own learning goals and provide several voluntary learning recommendations to increase students' choice and relevance of learning content. Learning analytics systems should serve appropriate learning recommendations and self-assessments, in line with individual capabilities and ones that do not cause overextension but lead to a challenge and thus to increased curiosity, intrinsic motivation, increased perceived competence, and higher self-efficacy beliefs (Hau and Marsh 2015; Keller 2008a). Real-time feedback on current performance and progress towards goals can increase students' perceived confidence in successfully fulfilling the learning requirements and thus lead to strategy adjustments, and ideally to better learning outcomes. However, if students are struggling, the system may provide appropriate guidance on how to reach the designated learning objectives. The feedback could also influence students' dispositions on their learning outcome, leading to changes in upcoming pre-actional phases of motivation (Ifenthaler and Lehmann 2012). To increase learners' curiosity, various types of learning material such as videos, texts, podcasts, or external links are provided to meet all learners' preferences. Additionally, to increase the relevance of the learning content, learning analytics systems illustrate the connections between different learning content and previous learning artifacts. Furthermore, prompts can be used to investigate and to expand learners' motivation (Bannert 2009; Ifenthaler 2012).

Competitive environments might be perceived as reducing autonomy and so are related to a decrease of intrinsic motivation (Deci et al. 1996). A qualitative study investigating students' expectations on learning analytics features revealed differences in students' attitudes towards receiving analyses comparing their performance as it might reduce their motivation (Schumacher and Ifenthaler 2018). Especially for students who are not performing well in comparison with others, this information might impair their academic self-concept (social reference) and thus their self-efficacy beliefs and motivation. However, a feature comparing one's performance with those of others might be of interest to performance-approach oriented learners.

Considering the assumptions on motivation and (self-regulated) learning of Keller (2008b), Pintrich (2000c), and Zimmerman (2005, 2011), learning analytics can be supportive in initiating and sustaining learning motivation, as summarized in Table 2 .

\section{Research questions and hypotheses}

The purpose of this study is to investigate the relationship between students' motivational dispositions and their perceived support of learning analytics systems.

Depending on their goal orientations, students have different reasons for pursuing an achievement task (Pintrich 2000a), which leads to the use of varying learning 
Table 2 Learning analytics potential support on motivation in the cyclical phases of selfregulated learning

Forethought phase

Providing clear learning objectives and relating them to tasks

- Goals, goal setting; task value, interest

Connecting learning material to prior knowledge, previous course content, learning objectives, or external data (news, videos)

- Task value, interest, relevance

Offering skill matching but challenging tasks based on available data

- Curiosity, interest; outcome expectancies; self-efficacy

Motivational prompts if learners are not beginning to learn or not learning appropriately to reach goals

- Effort initiation

Comparison with peers and their learning activities

- Self-efficacy; performance goal orientation

Feedback on predicted learning outcomes

- Expectancies, self-efficacy beliefs

Feedback on previous learning outcomes and activities

- Self-efficacy; outcome expectations

Performance phase

Analyzing learner's motivational state based on behavior and by using prompts

- Early interventions to increase motivation

Offering different learning material (videos, slides, texts, external links, news)

- Arouses curiosity; autonomy/choice, interest

(Prompts) for self-assessments and inform learners about their current state of knowledge not grading

- Autonomy/control; effort regulation; help-seeking; effort initiation

Just-in-time feedback

- Outcome expectancies, learning actions, rewards, persistence

Feedback on progress towards learning objectives

- Self-rewards; positive/negative outcomes; reminds of goals

Providing appropriate learning recommendations on how to reach learning objectives

- Adapt strategies, effort persistence

Motivational prompts

- Motivation regulation, effort regulation, attention control

Advising to change learning environment (noise, light etc.)

- Attention control

Recommendation of learning partners dealing with the same problem

- Help seeking, social reference and embeddedness

Expected time for completing tasks

- Reward, pausing, monitoring

Self-reflection phase

Feedback about learning outcomes

- Attributions, self-efficacy beliefs 
Table 2 continued

Facilitating learner's evaluation of learning outcomes against goals/standards

- Satisfaction; leading to adaptive/defensive reactions

Recommendations about improvements for upcoming tasks

- Attributions, increase perceived control of outcomes, adapt strategies, prepare upcoming strategic planning

strategies and motivational sources. Thus, students' goal orientations also have an impact on their expectations towards support of their learning processes and motivational states. Therefore, it is hypothesized that students' learning goal orientation (Hypothesis 1a), performance-approach goal orientation (Hypothesis 1b), performance-avoidance goal orientation (Hypothesis 1c), and their workavoidance goal orientation (Hypothesis 1d) are related to their rating of perceived support from learning analytics.

Likewise, learners' anticipated abilities impact their interest, persistence, motivation to learn, and the learning strategies selected (Cook and Artino Jr 2016; Schunk et al. 2008). Depending on the predominant reference norm on which learners build their academic self-concept, they might demand different support in terms of motivation and learning. Thus, it is assumed that students' academic selfconcept based on individual reference (Hypothesis 2a), criterion-based reference (Hypothesis 2b), social reference (Hypothesis 2c), and without reference (Hypothesis 2d) significantly predict their rating of perceived support from learning analytics. Additionally, students' background (i.e., age, gender, final school grade), and study related characteristics (i.e., semester load, current study grade, study program) were reviewed for their influence on how they predicted the anticipated support from learning analytics (Hypothesis 3).

\section{Method}

\section{Participants and design}

We recruited a purposive sample of 802 students (472 female, 330 male) from a European university. Most students were enrolled in a Bachelor program $\left(n_{B A}=588\right)$, followed by Master students $\left(n_{M A}=137\right)$, and students in other study programs (e.g., diploma; $n_{\text {OTHER }}=77$ ). The participants were enrolled in economics and law $(56.6 \%)$, STEM (16.1\%), languages, culture and arts (13.5\%), social sciences (9.7\%), medicine (2.6\%), and other fields of study (.9\%) [4 missing responses]. Students were asked to participate in an online study that was implemented on the university's server. 


\section{Instruments}

\section{Learning and achievement motivation scales}

The scales for the assessment of learning and achievement motivation (Spinath et al. 2012) measured four factors: learning goal orientation, performance-approach goal orientation, performance-avoidance goal orientation, and work-avoidance goal orientation (31 items; split-half reliability ranging from .73 to .78).

\section{Academic self-concept scale}

The academic self-concept scale (Dickhäuser et al. 2002) measures academic selfconcept based on four factors: social, individual, criterion-oriented, and no reference norms (22 items; Cronbach's $\alpha$ ranging from .74 to .92).

\section{Expected learning analytics support}

The instrument consists of 20 items investigating how learning analytics may support learning (LAS; Cronbach's $\alpha=.936$ ). Sample items of LAS are "Learning analytics would help me to track my progress towards my learning goals", "Learning analytics would help me to facilitate my learning activities", "Learning analytics would help me to better analyze my learning outcomes". All items were answered on a 5-point Likert scale ( $1=$ strongly disagree; $2=$ disagree; $3=$ neither agree nor disagree; 4 = agree; 5 = strongly agree) .

\section{Demographic information}

Demographic information included gender, age, course load, study program (15 items in total).

\section{Procedure}

Students of various disciplines were invited to participate in the online study, which consisted of four parts. First, students answered questions about their learning and achievement motivation $(3.2 .2 .1 ; 8 \mathrm{~min})$. Second, they were asked to disclose information about their academic self-concept $(3.2 .2 .2 ; 7 \mathrm{~min})$. Then, they rated benefits they thought learning analytics systems could offer in order to support learning $(3.2 .2 .3 ; 6 \mathrm{~min})$. Finally, students revealed their demographic information $(3.2 .2 .4 ; 10 \mathrm{~min})$. 


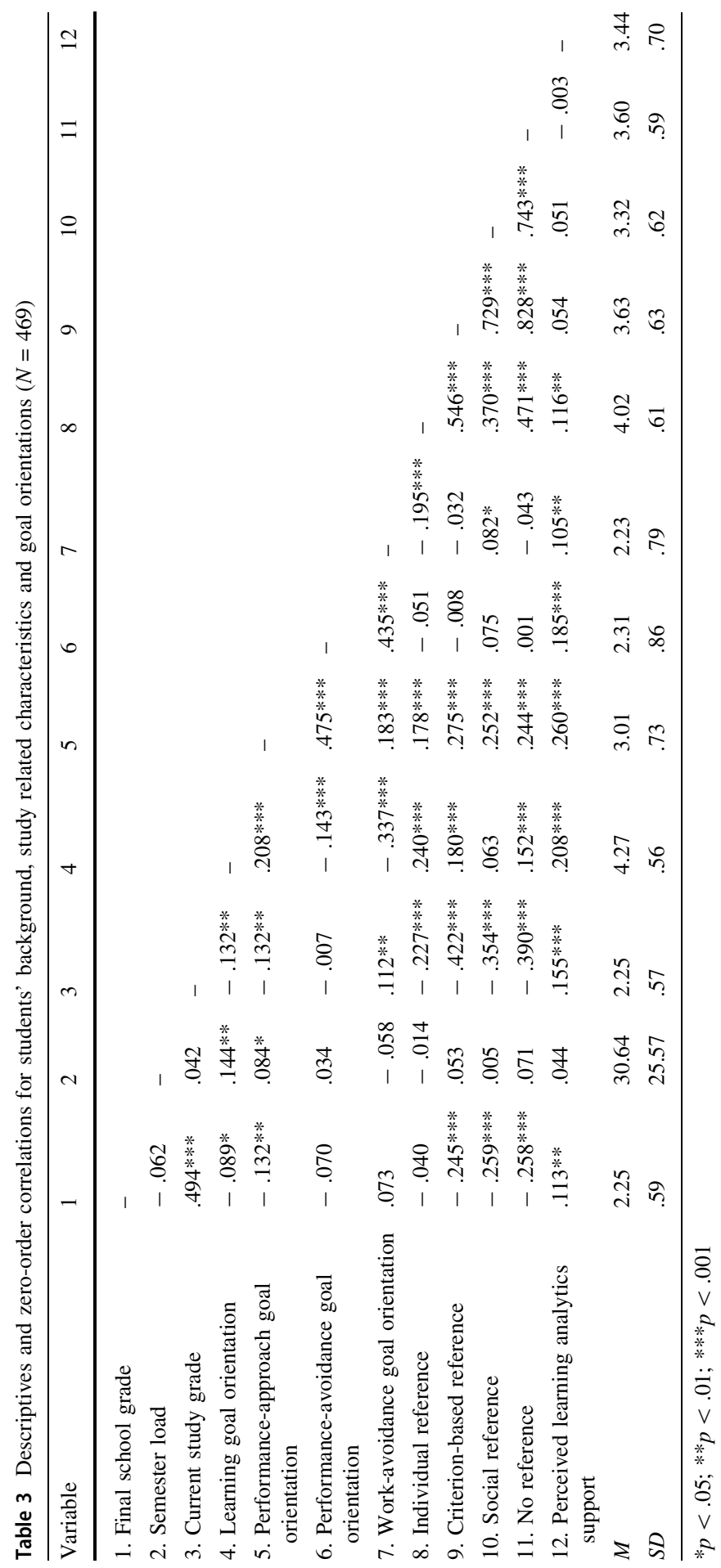




\section{Results}

Table 3 shows the descriptive statistics and zero-order correlations of predictors used in the regression analysis indicating significant correlations between students' background, study characteristics, goal orientations, academic self-concept, and perceived learning analytics support.

A hierarchical regression analysis was used to determine whether students' background (age, gender, final school grade), study-related characteristics (semester load, current study grade, study program), goal orientations (learning goal orientation, performance-approach goal orientation, performance-avoidance goal orientation, work-avoidance goal orientation), and academic self-concept (individual reference, criterion-based reference, social reference, no reference) were significant predictors of perceived learning analytics support. The results of the regression analyses for perceived learning analytics support are presented in Table 4 yielding a $\Delta R^{2}$ of $.183, F(14,454)=8.49, p<.001$. With regard to hypothesis 1a, students' learning goal orientation positively predicted the perceived learning analytics support, indicating that the higher the students' learning goal orientation, the higher the perceived support from learning analytics. Further, students' performance-approach goal orientation (Hypothesis 1b) positively

Table 4 Regression analysis for students' background, study related characteristics, goal orientations, and academic self-concept predicting perceived support from learning analytics $(N=469)$

\begin{tabular}{lrcc}
\hline & $B$ & $S E B$ & $\beta$ \\
\hline Perceived learning analytics support & & & \\
Students' background & & & .075 \\
Age & .025 & .016 & -.071 \\
Gender (0 = male) & -.101 & .062 & .022 \\
Final school grade & .026 & .061 & .001 \\
Study related characteristics & & & $.178^{* *}$ \\
Semester load & .000 & .001 & $-.178^{* * *}$ \\
Current study grade & .217 & .065 & $.206^{* * *}$ \\
Study program (1 = Bachelor) & -.308 & .086 & $.164^{* *}$ \\
Goal orientations & & & .102 \\
Learning goal orientation & .257 & .060 & .093 \\
Performance-approach goal orientation & .156 & .050 & $.115^{*}$ \\
Performance-avoidance goal orientation & .082 & .043 & .091 \\
Work-avoidance goal orientation & .082 & .045 & .079 \\
Academic self-concept & & & $-.170^{*}$ \\
Individual reference & .132 & .061 & \\
Criterion-based reference & .101 & .095 & .076 \\
Social reference & .089 & .095 & \\
No reference & -.200 & & \\
\hline
\end{tabular}

$* p<.05 ; * * p<.01 ; * * * p<.001$ 
predicted the perceived learning analytics support, indicating that the higher the students' performance-approach goal orientation, the higher the perceived support from learning analytics. With regard to hypothesis $2 \mathrm{a}$, students' individual reference orientation positively predicted the perceived learning analytics support, indicating that the higher the students' individual reference norm, the higher the perceived support from learning analytics. Finally, students' no reference $(\mathrm{H} 2 \mathrm{~d})$ orientation negatively predicted the perceived learning analytics support, indicating that the lower students' no reference norm, the higher the perceived support from learning analytics. With regard to hypothesis 3, no significant predictors related to students' background could be identified. However, current study grade positively predicted the perceived learning analytics support, indicating that the weaker the students' study performance, the higher the support from learning analytics is perceived. In addition, study program negatively predicted the perceived learning analytics support, indicating that students in lower semester levels expect higher support from learning analytics systems.

To sum up, Hypothesis 1 is accepted for students' goal orientations (learning goal orientation (H1a), performance-approach goal orientation (H1b)), Hypothesis 2 is accepted for students' academic self-concept (individual reference orientation $(\mathrm{H} 2 \mathrm{a})$, no reference orientation $(\mathrm{H} 2 \mathrm{~d})$ ), and Hypothesis 3 is accepted for current study grade and study program.

\section{Discussion}

Research on motivation particularly emphasizes the influence of self-efficacy, selfdetermination, and goal orientation on the quality and outcome of learning (Dickhäuser et al. 2002; Ryan and Deci 2000; Zimmerman and Campillo 2003; Zimmerman et al. 2017). Further, research on motivation draws on several wellestablished theoretical perspectives, such as expectancy value theory (Wigfield and Eccles 2000), attribution theory (Weiner 1985), social-cognitive theory (Bandura 1977), goal-orientation theory (Dweck and Leggett 1988; Elliot 2005), or selfdetermination theory (Deci and Ryan 1991). Contemporary motivational theories influencing research in learning sciences recognize that aspects that motivate one learner might not motivate another (Svinicki and Vogler 2012). Furthermore, modern theories of motivation presume the intentionality of human behavior: people are motivated when they are willing to achieve a certain future state (Deci and Ryan 1991). Especially in online learning environments and higher education motivation of students needs to be considered already when designing the learning environment. Therefore, Keller's theory (2008b) which includes relevant theoretical concepts such as volition, motivation, learning and performance can be used as a guiding framework. As recent empirical findings in the field of learning analytics document a successful implementation relies on a broad variety of information about individual learners, such as their motivational dispositions as well as individual characteristics (Ifenthaler and Widanapathirana 2014). Hence, to adapt the learning environment to students' (motivational) needs the design of learning 
environments can be iteratively informed by learning analytics (Ifenthaler 2017; Ifenthaler et al. 2018).

In this study, learning goal orientation and performance-approach goal orientation significantly predicted the perceived support from learning analytics. As these two goal orientations are related to either deeper interest and learning strategies or higher academic achievement (Harackiewicz et al. 1998), students assumed more benefits in terms of supporting learning and motivation. However, students with learning goal orientation and performance-approach goal orientation might demand different support (Duffy and Azevedo 2015). The former might ask for challenging tasks and additional resources, as they are interested in increasing their knowledge and skills (Zimmerman and Schunk 2008). Whereas the latter might prefer social comparisons related to performance, progress, used material, etc. (Seifert and O'Keefe 2001) to achieve the designated outcome and outperform others.

The students with performance-avoidance and work-avoidance goal orientation seem not to anticipate support from learning analytics. Nevertheless, it could be especially necessary to point out learning analytics benefit to theses learners as they might particularly risk a lack of motivation to learn or be less able to apply suitable learning strategies and achieve favorable results (Meece et al. 1988; Pintrich 2000b; Wolters 2003). Thus, further research should investigate differences in terms of motivational dispositions and preferred learning analytics features. Table 2 presents potential learning analytics features related to the three phases of self-regulated learning which may support learners' motivation. The identified features can serve as basis for designing learning analytics systems and for further (experimental) studies on potential differences of students' engagement with and perceptions of these features related to their motivational dispositions. Additionally, research should also be complemented by considering other motivational constructs. Support provided in online learning environments which is not aligned with students' needs might even lead to negative learning outcomes (Chen and Jang 2010). Support such as scaffolding had a positive impact on learning and achievement of students with performance-approach goal orientation but not or rather a negative impact on students' learning outcomes when adopting learningapproach goals (Duffy and Azevedo 2015). This emphasizes further the necessity to investigate the relation of motivational dispositions and (perceived) support from learning analytics in terms of learning processes and outcomes.

Regarding the academic self-concept beliefs, students with an individual reference norm assume that they could benefit from learning analytics. Students who build their academic self-concept upon comparisons with their own work might be interested in learning analytics for contrasting previous performance with current performance. Surprisingly students with criterion-based and social reference seem not to assume benefits from learning analytics. And furthermore, students whose academic self-concept is based on a more general reference (no reference norm), which is considered to include the other reference norms (Dickhäuser et al. 2002), perceive reverse benefits. Thus, a deeper analysis differentiating the various benefits of learning analytics or relating them to offered learning analytics features might lead to a more profound understanding of learners' perceived support from learning analytics. 
Furthermore, the results indicated that students with lower academic performance perceive more support from learning analytics. Thus, learning analytics seem to these students a meaningful support to their performance and how they could improve their learning approach, which both impact motivation as well. The guiding character of learning analytics is also indicated by the result that undergraduate students anticipate more support from learning analytics than more experienced Master students.

The present study has obvious limitations as self-reported measurements are used to assess students' motivational dispositions and as the focus is on only two motivational concepts. Furthermore, the students were not able to use a learning analytics system, thus, the perceived support was based on a hypothetical system, which might lead to biases. Additionally, even though the sample size was appropriate using a purposive sample by actively approaching students to participate in this study without ensuring representativity of age, gender, study subject, etc. might lead to biases due to self-selection and hence to difficulties in generalizability.

Learning analytics need to combine trace data and psychological inventories and thus allow further investigation of the reciprocal relation of motivation and selfregulated learning activities of students when engaging in online learning environments (Ellis et al. 2017; Lonn et al. 2015; Winne and Baker 2013; Zimmerman 2008). Such a holistic application of learning analytics may lead to a better understanding of motivation and learning processes and thus enables the creation of adaptable and personalized learning environments that meet learners' individual needs (Ifenthaler and Widanapathirana 2014). However, establishing valid and economic indicators on student motivation for learning analytics requires further research to ascertain when and how to measure motivational states taking account of its' processual character related to the other components of self-regulated learning (Moos and Stewart 2013). As learning analytics currently already provide feedback to students such as results of comparisons with peers or forecasts about their final course performance (Gašević et al. 2015), the impact of timing and content of feedback on learning motivation needs to be examined in future research. For further insights into students' responses to feedback, analyzing trace data seems to be a promising approach (Zimmerman 2008). For example, investigating students' behavioral patterns when dealing with learning materials, prompts or analyses of the learning analytics system related to their motivational dispositions might allow a higher adaptivity of learning analytics (Liu et al. 2017).

\section{Conclusion}

Learners differ in their reasons for engaging in achievement tasks and thus seem to expect different support while learning (Schunk and Zimmerman 2008). The findings of this study indicate that motivational dispositions such as goal orientation and academic self-concept as well as study-related characteristics impact students' perceived support from learning analytics. As the focus of learning analytics is on supporting learning where motivation is a crucial factor, students' motivation needs to be taken into account when designing learning analytics systems. This need is 
further supported by the assumption of motivation being a result of individual as well as environmental factors (Svinicki and Vogler 2012). A study conducted by Lonn et al. (2015) found that confronting students at risk in a summer bridge course with feedback from an early warning system led to a decrease of their learning goal orientation. As learning goal orientation is positively associated with intrinsic motivation and learning outcomes, this emphasizes the need to consider motivational dispositions of students when designing learning analytics. Hence, improving alignment with the needs of learners and their individual characteristics, personalization, and adaptivity are considered to be important, and for that, a broad data source is required (Ifenthaler and Widanapathirana 2014; Schumacher and Ifenthaler 2018). The appropriateness of learning analytics interventions and feedback is vital as a balance between guidance and autonomy is to be achieved that is not overcharging students' capabilities to self-regulate or impairing their motivation. However, to allow personalized learning analytics features considering students' motivational dispositions, appropriate indicators and data sources (e.g., inventories, physiological measures) need to identified to make this information available for learning analytics algorithms.

Acknowledgements The authors acknowledge the financial support by the Federal Ministry of Education and Research of Germany (BMBF, project number 16DHL1038).

\section{Compliance with ethical standards}

Conflict of interest The authors declare that they have no conflict of interest.

Open Access This article is distributed under the terms of the Creative Commons Attribution 4.0 International License (http://creativecommons.org/licenses/by/4.0/), which permits unrestricted use, distribution, and reproduction in any medium, provided you give appropriate credit to the original author(s) and the source, provide a link to the Creative Commons license, and indicate if changes were made.

\section{References}

Astleitner, H. (2000). Designing emotionally sound instruction: The FEASP-approach. Instructional Science, 28(3), 169-198. https://doi.org/10.1023/A:1003893915778.

Bandura, A. (1977). Self-efficacy: Toward a unifying theory of behavioral change. Psychological Review, 84(2), 191-215.

Bandura, A. (1993). Perceived self-efficacy in cognitive development and functioning. Educational Psychologist, 28(2), 117-148.

Bandura, A. (1994). Self-efficacy. In V. S. Ramachandran (Ed.), Encyclopedia of human behavior (pp. 71-81). New York: Academic Press.

Bannert, M. (2009). Promoting self-regulated learning through prompts. Zeitschrift für Pädagogische Psychologie, 23(2), 139-145.

Berland, M., Baker, R. S., \& Bilkstein, P. (2014). Educational data mining and learning analytics: Applications to constructionist research. Technology, Knowledge and Learning, 19(1-2), 205-220.

Boekaerts, M. (1999). Self-regulated learning: Where we are today. International Journal of Educational Research, 31(6), 445-457.

Bong, M., \& Skaalvik, E. M. (2003). Academic self-concept and self-efficacy: How different are they really? Educational Psychology Review, 15(1), 1-40.

Chen, K.-C., \& Jang, S.-J. (2010). Motivation in online learning: Testing a model of self-determination theory. Computers in Human Behavior, 26, 741-752. https://doi.org/10.1016/j.chb.2010.01.011. 
Cook, D. A., \& Artino, A. R., Jr. (2016). Motivation to learn: An overview of contemporary theories. Medical Education, 50, 997-1014.

Corno, L. (1993). The best-laid plans. Modern conceptions of volition and educational research. Educational Researcher, 22, 14-22.

Corrin, L., \& da Barba, P. (2014). Exploring students' interpretation of feedback delivered through learning analytics dashboards. In Proceedings of the ascilite 2014 conference (pp. 629-633).

Costa, E. B., Fonseca, B., Santana, M. A., de Araújo, F., \& Rego, J. (2017). Evaluating the effectiveness of educational data mining techniques for early prediction of students' academic failure in introductory programming courses. Computers in Human Behavior, 73, 247-256. https://doi.org/10. 1016/j.chb.2017.01.047.

d'Aquin, M., Dietze, S., Herder, E., Drachsler, H., \& Taibi, D. (2014). Using linked data in learning analytics. eLearning Papers, 36, 1-9.

Deci, E. L., \& Ryan, R. M. (1991). A motivational approach to self: Integration in personality. In R. A. Dienstbier (Ed.), Nebraska symposium on motivation: Perspectives on motivation (Vol. 38, pp. 237-288). Lincoln: University of Nebraska.

Deci, E. L., \& Ryan, P. R. (2008). Self-determination theory: A macrotheory of human motivation, development, and health. Canadian Psychology, 49(3), 182-185. https://doi.org/10.1037/a0012801.

Deci, E. L., Ryan, R. M., \& Williams, G. C. (1996). Need satisfaction and the self-regulation of learning. Learning and individual differences, 6(3), 165-183.

Dickhäuser, O., Schöne, C., Spinath, B., \& Stiensmeier-Pelster, J. (2002). Die Skalen zum akademischen Selbstkonzept. Zeitschrift für Differentielle und Diagnostische Psychologie, 23, 393-405. https:// doi.org/10.1024//0170-1789.23.4.393.

Drachsler, H., \& Greller, W. (2016). Privacy and analytics-It's a DELICATE issue. A checklist for trusted learning analytics. Paper presented at the Sixth International Conference on Learning Analytics \& Knowledge, Edinburgh, UK.

Duffy, M. C., \& Azevedo, R. (2015). Motivation matters: Interactions between achievement goals and agent scaffolding for self-regulate learning with an intelligent tutoring system. Computers in Human Behavior, 52, 338-348. https://doi.org/10.1016/j.chb.2015.05.041.

Dweck, C. S., \& Leggett, E. L. (1988). A social-cognitive approach to motivation and personality. Psychological Review, 95(2), 256-273.

Eccles, J. S., \& Wigfield, A. (2002). Motvational beliefs, values, and goals. Annual Review of Psychology, 53, 109-132.

Elliot, A. J. (1999). Approach and avoidance motivation and achievement goals. Educational Psychologist, 34(3), 169-189.

Elliot, A. J. (2005). A conceptual history of the achievement goal construct. In A. J. Elliot \& C. S. Dweck (Eds.), Handbook of competence and motivation (pp. 52-72). New York: Guilford Press.

Elliot, A. J., \& Hulleman, C. S. (2017). Achievement goals. In A. J. Elliot (Ed.), Handbook of competence and motivation (2nd ed., pp. 43-60). New York, NY: Guilford Press.

Elliot, A. J., Murayama, K., \& Pekrun, R. (2011). A $3 \times 2$ achievement goal model. Journal of Educational Psychology, 103(3), 632-648.

Ellis, R. A., Han, F., \& Pardo, A. (2017). Improving learning analytics-Combining observational data and self-report data on student learning. Educational Technolgy \& Society, 20(3), 158-169.

Engelschalk, T., Steuer, G., \& Dresel, M. (2016). Effectiveness of motivational regulation: Dependence on specific motivational problems. Learning and individual differences, 52, 72-78. https://doi.org/ 10.1016/j.lindif.2016.10.011.

Eseryel, D., Law, V., Ifenthaler, D., Ge, X., \& Miller, R. (2014). An investigation of the interrelationships between motivation, engagement, and complex problem solving in game-based learning. Educational Technolgy \& Society, 17(1), 42-53.

Ferla, J., \& Valcke, M. (2009). Academic self-efficacy and academic self-concept: Reconsidering structural relationships. Learning and individual differences, 19, 499-505.

Gašević, D., Dawson, S., \& Siemens, G. (2015). Let's not forget: Learning analytics are about learning. TechTrends, 59(1), 64-71. https://doi.org/10.1007/s11528-014-0822-x.

Gašević, D., Jovanovic, J., Pardo, A., \& Dawson, S. (2017). Detecting learning strategies with analytics: Links with self-reported measures and academic performance. Journal of Learning Analytics, 4(2), 113-128. https://doi.org/10.18608/jla.2017.42.10.

Harackiewicz, J. M., Barron, K. E., Carter, S. M., Lehto, A. T., \& Elliot, A. J. (1997). Predictors and consequences of achievement goals in the college classroom: Maintaining interest and making the grade. Journal of Personality and Social Psychology, 73(6), 1284-1295. 
Harackiewicz, J. M., Barron, K. E., \& Elliot, A. J. (1998). Rethinking achievement goals: When are they adaptive for college students and why? Educational Psychologist, 33(1), 1-21.

Hartnett, M., George, A. S., \& Dron, J. (2011). Examining motivation in online distance learning environments: Complex, multifaceted, and situation-dependent. The International Review of Research in Open and Distributed Learning, 12(6), 20-38.

Hau, K.-T., \& Marsh, H. W. (2015). Academic self-concept and achievement. In J. D. Wright (Ed.), International encyclopedia of the social \& behavioral sciences (2nd ed., Vol. 1, pp. 54-63). Amsterdam: Elsevier.

Ifenthaler, D. (2012). Determining the effectiveness of prompts for self-regulated learning in problemsolving scenarios. Journal of Educational Technology \& Society, 15(1), 38-52.

Ifenthaler, D., \& Lehmann, T. (2012). Preactional self-regulation as a tool for successful problem solving and learning. Technology, Instruction, Cognition \& Learning, 9(1-2), 97-110.

Ifenthaler, D., \& Widanapathirana, C. (2014). Development and validation of a learning analytics framework: Two case studies using support vector machines. Technology, Knowledge and Learning, 19(1-2), 221-240. https://doi.org/10.1007/s10758-014-9226-4.

Ifenthaler, D. (2015). Learning analytics. In J. M. Spector (Ed.), The Sage encyclopedia of educational technology (Vol. 2, pp. 447-451). Los Angeles, California: Sage Publications.

Ifenthaler, D., \& Schumacher, C. (2016). Student perceptions of privacy principles for learning analytics. Educational Technology Research and Development, 64(5), 923-938. https://doi.org/10. 1007/s11423-016-9477-y.

Ifenthaler, D. (2017). Learning analytics design. In L. Lin \& J. M. Spector (Eds.), Constructive articulation between the sciences of learning and the instructional design and technology communities (pp. 202-211). New York, NY: Routledge.

Ifenthaler, D., Gibson, D., \& Dobozy, E. (2018). Informing learning design through analytics: Applying network graph analysis. Australasian Journal of Educational Technology, 34(2), 117-132. https:// doi.org/10.14742/ajet.3767.

Joo, Y. J., Oh, E., \& Kim, S. M. (2015). Motivation, instructional design, flow, and academic achievement at a Korean online university: A structural equation modeling study. Journal of Computing in Higher Education, 27(1), 28-46.

Keller, J. M. (1987). Development and use of the ARCS model of instructional design. Journal of Instructional Development, 10(3), 2-10.

Keller, J. M. (2008a). First principles of motivation to learn and e3-learning. Distance Education, 29(2), $175-185$.

Keller, J. M. (2008b). An integrative theory of motivation, volition, and performance. Technology, Instruction, Cognition \& Learning, 6(2), 79-104.

Keller, J. M., \& Suzuki, K. (2004). Learner motivation and e-learning design: A multinationally validated process. Journal of Educational Media, 29(3), 229-239.

Lehmann, T., Hähnlein, I., \& Ifenthaler, D. (2014). Cognitive, metacognitive and motivational perspectives on preflection in self-regulated online learning. Computers in Human Behavior, 32, 313-323.

Li, K., \& Keller, J. M. (2018). Use of the ARCS model in education: A literature review. Computers \& Education, 122, 54-62. https://doi.org/10.1016/j.compedu.2018.03.019.

Linnenbrink-Garcia, L., Tyson, D. F., \& Patall, E. A. (2008). When are achievement goal orientations beneficial for academic achievement? A closer look at main effects and moderating factors. Revue international de psychologie sociale, 21(1/2), 19-79.

Liu, M., Kang, J., Zou, W., Lee, H., Pan, Z., \& Corliss, S. (2017). Using data to understand how to better design adaptive learning. Technology, Knowledge and Learning, 22, 271-298. https://doi.org/10. 1007/s10758-017-9326-Z.

Long, P., \& Siemens, G. (2011). Penetrating the fog. Analytics in learning and education. Educause Review, 46(5), 31-40.

Lonn, S., Aguilar, S. J., \& Teasley, S. D. (2015). Investigating student motivation in the context of learning analytics intervention during a summer bridge program. Computers in Human Behavior, 47, 90-97. https://doi.org/10.1016/j.chb.2014.07.013.

Mah, D.-K. (2016). Learning analytics and digital badges: Potential impact on student retention in higher education. Technology, Knowledge and Learning, 21(3), 285-305.

Marzouk, Z., Rakovic, M., Liaqat, A., Vytasek, J., Samadi, D., Stewart-Alonso, J., et al. (2016). What if learning analytics were based on learning science? Australasian Journal of Educational Technology, 32(6), 1-18. https://doi.org/10.14742/ajet.3058. 
Meece, J. L., Bluemenfeld, P. C., \& Hoyle, R. H. (1988). Students' goal orientations and cognitive engagement in classroom activities. Journal of Educational Psychology, 80(4), 514-523.

Moos, D. C., \& Bonde, C. (2016). Flipping the classroom: Embedding self-regulated learning prompts in videos. Technology, Knowledge and Learning, 2016, 225-242. https://doi.org/10.1007/s10758-0159269-1.

Moos, D. C., \& Stewart, C. A. (2013). Self-regulated learning with hypermedia: Bringing motivation into the conversation. In R. Azevedo \& V. Aleven (Eds.), International handbook of metacognition and learning technologies (pp. 683-695). New York, NY: Springer.

Park, Y., \& Jo, I.-H. (2015). Development of the learning analytics dashboard to support students' learning performance. Journal of Universal Computer Science, 21(1), 110-133.

Pintrich, P. R. (1999). The role of motivation in promoting and sustaining self-regulated learning. International Journal of Educational Research, 31, 459-470.

Pintrich, P. R. (2000a). An achievement goal theory perspective on issues in motivation terminology, theory, and research. Contemporary Educational Psychology, 25, 92-104.

Pintrich, P. R. (2000b). Multiple goals, multiple pathways: The role of goal orientation in learning and achievement. Journal of Educational Psychology, 92(3), 544-555.

Pintrich, P. R. (2000c). The role of goal orientation in self-regulated learning. In M. Boekaerts, P. R. Pintrich, \& M. Zeidner (Eds.), Handbook of Self-regulation (pp. 451-502). San Diego, CA: Academic Press.

Roberts, L. D., Howell, J. A., \& Seaman, K. (2017). Give me a customizable dashboard: Personalized learning analytics dashboards in higher education. Technology, Knowledge and Learning, 22, 317-333. https://doi.org/10.1007/s10758-017-9316-1.

Rubel, A., \& Jones, K. M. L. (2016). Student privacy in learning analytics: An information ethics perspective. The Information Society, 32(2), 143-159. https://doi.org/10.1080/01972243.2016. 1130502.

Ryan, R. M., \& Deci, E. L. (2000). Self-determination theory and the facilitation of intrinsic motivation, social development, and well-being. American Psychologist, 55(1), 68-78.

Schumacher, C., \& Ifenthaler, D. (2018). Features students really expect from learning analytics. Computers in Human Behavior, 78, 397-407. https://doi.org/10.1016/j.chb.2017.06.030.

Schunk, D. H. (1991). Self-efficacy and academic Motivation. Educational Psychologist, 26(3\&4), 207-231.

Schunk, D. H. (2008). Attributions as motivators or self-regulated learning. In D. H. Schunk \& B. J. Zimmerman (Eds.), Motivation and self-regulated learning. Theory, research, and applications (pp. 245-266). New York, NY: Routledge.

Schunk, D. H., Pintrich, P. R., \& Meece, J. L. (2008). Motivation in education (3rd ed.). Upper Saddle River: Pearson/Merrill Prentice Hall.

Schunk, D. H., \& Zimmerman, B. J. (2008). Motivation and self-regulated learning: Theory, research, and applications. New York: Routledge.

Seifert, T. L., \& O'Keefe, B. A. (2001). The relationship of work avoidance and learning goals to perceived competence, externality and meaning. British Journal of Educational Psychology, 71, 81-92.

Senko, C., Hulleman, C. S., \& Harackiewicz, J. M. (2011). Achievement goal theory at the crossroads: Old controversies, current challenges, and new directions. Educational Psychologist, 46(1), 26-47. https://doi.org/10.1080/00461520.2011.538646.

Skaalvik, S., \& Skaalvik, E. M. (2005). Self-concept, motivational orientation, and help-seeking behavior in mathematics: A study of adults returning to high school. Social Pschology of Education, 8, 285-302.

Spinath, B., Stiensmeier-Pelster, J., Schöne, C., \& Dickhäuser, O. (2012). Die Skalen zur Erfassung von Lern- und Leistungsmotivation (SELLMO) (2nd ed.). Göttingen: Hogrefe.

Svinicki, M. D., \& Vogler, J. S. (2012). Motivation and learning: Modern theories. In N. M. Seel (Ed.), Encyclopedia of the sciences of learning (pp. 2336-2339). New York: Springer.

Van Yperen, N. W., Blaga, M., \& Postmes, T. (2014). A meta-analysis of self-reported achievement goals and nonself-report performance across three achievement domains (work, sports, and education). PLoS ONE, 9(4), 1-16. https://doi.org/10.1371/journal.pone.0093594.

Vansteenkiste, M., Simons, J., Lens, W., Sheldon, K. M., \& Deci, E. L. (2004). Motivating learning, performance, and persistence: The synergistic effects of intrinsic goal contents and autonomysupportive contexts. Journal of Personality and Social Psychology, 87(2), 246-260. 
Verbert, K., Duval, E., Klerkx, J., Govaerts, S., \& Santos, J. L. (2013). Learning analytics dashboard applications. American Behavioral Scientist, 57(10), 1500-1509.

Weidinger, A. F., Spinath, B., \& Steinmayr, R. (2016). Why does intrinsic motivation decline following negative feedback? The mediating role of ability self-concept and its moderation by goal orientations. Learning and individual differences, 47, 117-128.

Weiner, B. (1985). An attributional theory of achievement motivation and emotion. Psychological Review, 92(4), 548-573.

West, D., Huijser, H., \& Heath, D. (2016). Putting an ethical lens on learning analytics. Education Technology Research and Development, 64(5), 903-922. https://doi.org/10.1007/s11423-016-94643.

Wigfield, A., \& Eccles, J. S. (2000). Expectancy value theory of achievement motivation. Contemporary Educational Psychology Review, 25, 68-81.

Wigfield, A., Tonks, S., \& Klauda, S. L. (2009). Expectancy-Value Theory. In K. R. Wentzel \& A. Wigfield (Eds.), Handbook of motivation at school. New York, NY: Routledge.

Winne, P. H., \& Baker, R. S. J. D. (2013). The potentials of educational data mining for researching metacognition, motivation and self-regulated learning. Journal of Educational Data Mining, 5(1), $1-8$.

Winne, P. H., \& Hadwin, A. F. (2008). The weave of motivation and self-regulated learning. In D. H. Schunk \& B. J. Zimmerman (Eds.), Motivation and self-regulated learning: Theory, research, and applications (pp. 297-314). New York: Routledge.

Wolters, C. A. (1998). Self-regulated learning and college students' regulation of motivation. Journal of Educational Psychology, 90(2), 224-235.

Wolters, C. A. (2003). Understanding procrastination from a self-regulated learnig perspective. Journal of Educational Psychology, 95(1), 179-187.

Zimmerman, B. J. (1990). Self-regulated learning and academic achievement: An overview. Educational Psychologist, 25(1), 3-17.

Zimmerman, B. J. (2002). Becoming a self-regulated learner: An overview. Theory into Practice, 41(2), 64-70.

Zimmerman, B. J. (2005). Attaining self-regulation. A social cognitive perspective. In M. Boekaerts, P. R. Pintrich, \& M. Zeidner (Eds.), Handbook of self-regulation (pp. 13-39). San Diego: Academic Press.

Zimmerman, B. J. (2008). Investigating self-regulated learning and motivation: Historical background, methodological developments, and future prosepects. American Educational Research Journal, 45(1), 166-183.

Zimmerman, B. J. (2011). Motivational sources and outcomes of self-regulated learning and performance. In B. J. Zimmerman \& D. H. Schunk (Eds.), Handbook of self-regulation of learning and performance (pp. 49-64). New York, NY: Routledge.

Zimmerman, B. J., \& Campillo, M. (2003). Motivating self-regulated problem solvers. In J. E. Davidson \& R. J. Sternberg (Eds.), The psychology of problem solving (pp. 233-262). Cambridge: Cambridge University Press.

Zimmerman, B. J., \& Schunk, D. H. (2008). Motivation an essential dimension of self-regulated learning. In D. H. Schunk \& B. J. Zimmerman (Eds.), Motivation and self-regulated learning: Theory, research, and applications (pp. 1-30). New York: Routledge.

Zimmerman, B. J., Schunk, D. H., \& DiBenedetto, M. K. (2017). The role of self-efficacy and related beliefs in self-regulation of Learning and Performance. In A. J. Elliot (Ed.), Handbook of competence and motivation (2nd ed., pp. 313-333). New York, NY: Guilford Press.

Clara Schumacher is research assistant at the chair of Economic and Business Education - Learning, Design and Technology at the University of Mannheim. Her research interests focus on educational technology, self-regulated learning, learning analytics and informal learning.

Dirk Ifenthaler is Chair and Professor of Learning, Design and Technology at University of Mannheim, Germany and UNESCO Deputy Chair of Data Science in Higher Education Learning and Teaching, Curtin University, Australia. His research focuses on the intersection of cognitive psychology, educational technology, data analytics, and organizational learning. 